\title{
Deep-Seated Landslides
}

\author{
Giovanni Barla ${ }^{1}$
}

Published online: 18 May 2016

(c) Springer-Verlag Wien 2016

The Editorial of the November 2013 issue of Rock Mechanics and Rock Engineering (Volume 46-Number 6-November 2013) was written to bring to mind the 50th Anniversary of the Vajont Landslide, which occurred on October 9, 1963. On that occasion, we invited our readers to submit papers dealing with novel and specialized topics on Deep-Seated Landslides. These papers were peer-reviewed for publication in this special issue following this editorial.

A wide range of topics is covered starting with the description of selected landslides in different countries. The importance of performing accurate geological fieldwork and sound analysis is underlined for the understanding of the geological and geomorphic processes. The main purpose is to define a sound geological reference model and share light on landslide mechanisms.

Different landslides are described such as block slides developing on extremely weak, thin clay seams, parallel to bedding in gently dipping sandstones and mudstone. Also described are compound landslides interacting with reservoirs with signs of gravitational and water impoundment induced deformations. Field observations, conventional and advanced monitoring methods, limit equilibrium analysis and continuum-discontinuum modeling are used to share light on how slope instability may develop.

The case of slow-moving landslides interacting with inhabited areas and infrastructure such as tunnels is analyzed based on field observations, different monitoring data, laboratory tests and modeling. These problems are investigated in the framework of disaster and emergency

\footnotetext{
Giovanni Barla

giovanni.barla@polito.it

1 Politecnico di Torino, Turin, Italy
}

management also in view of possible resettling of people to new areas.

Hydromechanical cycling, progressive failure and fatigue phenomena are discussed to explain the episodic behavior of deep-seated landslides. Advanced numerical models are used for studying such a complex type of behavior. When calibrated against slope monitoring data, these models may contribute to an improved understanding of slope movements and lead to early warning forecasting and improved landslide hazard management.

Significant advances in the modeling of flow-like landslides and rock avalanches as a key component of landslides risk assessment and management were presented. It is shown, with different runout models applied to real events, how rock avalanches are simulated while accounting for the influence of the rheology on the avalanche properties. The sets of benchmarks discussed provide information on the proposed model accuracy and limitations.

The stability conditions and the post-failure behavior of a complex landslide with geometry inspired by representative cross sections of the Vajont landslide were analyzed. It is shown that the instability is triggered by an increase of pore water pressure leading to a progressive failure mechanism developing along a shear surface. It is demonstrated that if no shearing strength is considered (as shown by a thermal pressurization analysis) the model predicts a response similar to actual observations.

Specific advanced research topics dealing with the Vajont deep-seated landslide are discussed such as the important transition from ductile to brittle behavior of large unstable rock slopes. The modeling of the landslide spreading and the impact on a water surface with the generation of the impulse waves is as well presented, 
including the simulation of the landslide evolution, its propagation and interaction with a water reservoir.

Finally, the attention moves to the study of the seismic effects on deep-seated landslides, including rock mass fatigue as a mechanism contributing to progressive failure.
An integrated engineering geomorphology mapping and numerical modeling approach applied to the investigation of geomorphic and seismic effects is described. Also discussed are case studies on large-scale slope failures, induced by recent earthquakes. 